\title{
A pilot double-blind, randomized, placebo- controlled trial of the efficacy of trace elements in the treatment of endometriosis-related pain: study design and methodology
}

\author{
This article was published in the following Dove Press journal: \\ Nutrition and Dietary Supplements \\ 10 February 2016 \\ Number of times this article has been viewed
}

\section{Didier Oberweis' \\ Patrick Madelenat ${ }^{2}$ \\ Michelle Nisolle ${ }^{3}$ \\ Etienne Demanet ${ }^{4}$}

'Department of Gynecology and Obstetrics, $\mathrm{CHU}$ de Charleroi, Hôpital André Vésale, Montigny-leTilleul, Belgium; ${ }^{2}$ Private Consultation,

Paris, France; ${ }^{3}$ Department of Gynecology and Obstetrics, CHR Citadelle, Liège, ${ }^{4}$ Clinical Research Unit, Charleroi, Belgium
Correspondence: Didier Oberweis Department of Gynecology and Obstetrics, $\mathrm{CHU}$ de Charleroi, Hôpital André Vésale, 706 Route de Gozée, B-6I I0 Montigny-le-Tilleul, Belgium Tel +32 7l 922476

Email Didier.Oberweis@chu-charleroi.be

\begin{abstract}
Endometriosis is one of the most common benign gynecological disorders, affecting almost $10 \%-15 \%$ of all women of reproductive age and $>30 \%$ of infertile women. The pathology is associated with various distressing symptoms, particularly pelvic pain, which adversely affect patients' quality of life. It is an estrogen-dependent disease. There is evidence both in animals and in humans that metal ions can activate the estrogen receptors. They are defined as a variety of xenoestrogens, called metalloestrogens, which could act as endocrine disruptors. Therefore, it could be considered to act on this gynecological disorder using food supplements containing trace elements (ie, nutripuncture). The assumption is that they could modulate estrogen receptors and thus influence the tropism and the survival of cells involved in endometriosis. By a modulation of the antioxidant system, they might also interact with various parameters influencing tissue biochemistry. The objective of this article is to describe and discuss the design and methodology of an ongoing double-blind, randomized, placebo-controlled study aiming to evaluate the efficacy of metal trace elements on the reduction of pain and improvement of quality of life, in patients with a revised American Fertility Society Score Stages II-IV endometriosis, combined or not with adenomyosis, during a treatment period of 4 months. Trace elements or placebo is proposed in the absence of any other treatment or as an add-on to current therapies, such as sexual hormones, nonsteroidal anti-inflammatory drugs, and surgery. A placebo run-in period of one menstrual cycle or 30 days for women in amenorrhea has been scheduled to eliminate the patients who are responding too much to the placebo. After a 1:1 ratio randomization on Day 0, the treatment with trace elements or placebo will last for 4 months (120 days).
\end{abstract}

Keywords: endometriosis, trace elements, randomized, placebo-controlled study, pain, quality of life

\section{Introduction}

Endometriosis is defined as the presence of endometrial tissue, including both glandular epithelium and stroma, outside the uterine cavity. If the prevalence of endometriosis in specific categories of patients has been reported, the real prevalence in the general population is not known ${ }^{1}$ but is one of the most common benign gynecological disorders, affecting almost $10 \%-15 \%$ of all women of reproductive age and $>30 \%$ of infertile women. ${ }^{2,3}$ It is associated with various distressing symptoms, such as dysmenorrhea, dyspareunia, pelvic pain, and subfertility, which adversely affect patients' quality of life (QoL). A growing body of evidence suggests that a combination of genetic, hormonal, environmental, immunological, and anatomical factors plays a role in the pathogenesis of this disorder. ${ }^{4-6}$ 
There is a general agreement that if ablative surgery by laparoscopy is the treatment of choice for peritoneal lesions, conservative laparoscopic surgery is the treatment of choice for ovarian endometriotic cysts ${ }^{7,8}$ because medical treatment alone is insufficient. ${ }^{9}$ However, a frustrating aspect of laparoscopic excision is cyst recurrence after surgery, with a cumulative rate of endometrioma recurrence after 2-5 years of follow-up of $12 \%-30 \%{ }^{10}$

A recent overview has focused on 17 published Cochrane systematic reviews concerning the interventions for pain relief and for subfertility in premenopausal women with clinically diagnosed endometriosis. Suppression of menstrual cycles with gonadotrophin-releasing hormone $(\mathrm{GnRH})$ analogs, the levonorgestrel-releasing intrauterine system, and danazol were beneficial interventions. Laparoscopic treatment of endometriosis and excision of endometrioma were also associated with improvements in pain. The evidence on nonsteroidal anti-inflammatory drugs was inconclusive. In women with endometriosis undergoing assisted reproduction, 3 months of treatment with GnRH agonist improved pregnancy rates.
Excisional surgery improved spontaneous pregnancy rates within 9-12 months after surgery compared to ablative surgery. Laparoscopic surgery improved live birth and pregnancy rates compared to diagnostic laparoscopy alone. There was no evidence that medical treatment improved clinical pregnancy rates. Evidence on harms was scanty, but GnRH analogs, danazol, and depot progestagens were associated with higher rates than other interventions. ${ }^{11}$

Endometriosis is an estrogen-dependent disease. There is evidence both in animals and in humans that metal ions can activate the estrogen receptors. They are defined as a variety of xenoestrogens, called metalloestrogens, ${ }^{12-14}$ which could act as endocrine disruptors. ${ }^{6}$

Antioxidants could confer a certain protection against the endometriosis lesions, and trace elements could modify the oxidative stress levels with an impact on endometriosis..$^{15-18}$

The effects of major trace elements on endometriosis have been summarized in Table 1. They can have positive, negative, and/or mitigated effects on the disease or on the conditions leading to it. However, the situation is not so clear, and the vast

Table I Summary of the effects of the major trace elements (in alphabetical order) on endometriosis or on the potential conditions leading to the disease

\begin{tabular}{|c|c|c|c|}
\hline $\begin{array}{l}\text { Trace } \\
\text { element }\end{array}$ & $\begin{array}{l}\text { Short description of the } \\
\text { positive effects }\end{array}$ & $\begin{array}{l}\text { Short description of the negative } \\
\text { effects }\end{array}$ & $\begin{array}{l}\text { Short description of the mitigated } \\
\text { effects }\end{array}$ \\
\hline Boron & No data available & & \\
\hline Cadmium & $\begin{array}{l}\text { Clinical study: women suffering from } \\
\text { endometriosis presented cadmium } \\
\text { urine levels lower than the control } \\
\text { women }{ }^{26} \\
\text { No data available }\end{array}$ & $\begin{array}{l}\text { In vitro: cadmium can induce the } \\
\text { proliferation of stromal cells derived from } \\
\text { the eutopic endometrium of women with } \\
\text { endometriosis }{ }^{27} \\
\text { No data available }\end{array}$ & $\begin{array}{l}\text { Clinical study: data does not support } \\
\text { a role for cadmium in the onset or } \\
\text { the growth of endometriosis or deep } \\
\text { endometriotic (adenomyotic) nodules }{ }^{28,29} \\
\text { Case-control study: no association } \\
\text { between urinary cadmium } \\
\text { concentrations and the risk of } \\
\text { endometriosis }\end{array}$ \\
\hline \multirow[t]{2}{*}{ Calcium } & No data available & $\begin{array}{l}\text { Animal model: upregulation of calcium } \\
\text { channel in the spinal cord may contribute } \\
\text { to pelvic organ cross-sensitization in painful } \\
\text { endometriosis }{ }^{31}\end{array}$ & $\begin{array}{l}\text { Clinical study: no evidence of differences } \\
\text { in serum calcium concentrations } \\
\text { between women suffering from } \\
\text { endometriosis and control women }\end{array}$ \\
\hline & No data available & $\begin{array}{l}\text { Ex vivo study: calcium-binding proteins } \\
\text { seem to be increased in endometriosis- } \\
\text { associated nerve fibers and might play a role } \\
\text { in the chronic inflammatory condition and } \\
\text { the pain pathogenesis of endometriosis }{ }^{33}\end{array}$ & No data available \\
\hline Chloride & No data available & No data available & No data available \\
\hline Chrome & No data available & No data available & No data available \\
\hline Copper & No data available & $\begin{array}{l}\text { Clinical study: positive correlations were } \\
\text { found between copper and total oxidant } \\
\text { status and copper and oxidative stress } \\
\text { index. Copper appears to be associated } \\
\text { with the pathogenesis of and oxidative } \\
\text { stress in endometriosis }{ }^{34}\end{array}$ & $\begin{array}{l}\text { Ex vivo study: the expression of copper } \\
\text { superoxide dismutase in endometriosis } \\
\text { was persistently higher than the control } \\
\text { levels throughout the menstrual cycle }{ }^{35}\end{array}$ \\
\hline Fluorine & No data available & No data available & No data available \\
\hline lodine & No data available & No data available & No data available \\
\hline
\end{tabular}


Table I (Continued)

\begin{tabular}{|c|c|c|c|}
\hline $\begin{array}{l}\text { Trace } \\
\text { element }\end{array}$ & $\begin{array}{l}\text { Short description of the } \\
\text { positive effects }\end{array}$ & $\begin{array}{l}\text { Short description of the negative } \\
\text { effects }\end{array}$ & $\begin{array}{l}\text { Short description of the mitigated } \\
\text { effects }\end{array}$ \\
\hline \multirow[t]{4}{*}{ Iron } & No data available & $\begin{array}{l}\text { Ex vivo study: presence of iron-related } \\
\text { compounds that are potentially toxic to the } \\
\text { development of ovarian follicles adjacent } \\
\text { to the endometrioma during in vitro } \\
\text { fertilization }{ }^{36}\end{array}$ & $\begin{array}{l}\text { Ex vivo study: ectopic endometrial } \\
\text { stromal cells play a protective role for } \\
\text { cancer-target epithelial cells by collecting } \\
\text { excess iron }{ }^{37}\end{array}$ \\
\hline & No data available & $\begin{array}{l}\text { Ex vivo study: results suggest that iron } \\
\text { overload induces a proendometriotic } \\
\text { phenotype on healthy human endometrial } \\
\text { stromal cells, which could participate in the } \\
\text { endometriosis pathogenesis }\end{array}$ & $\begin{array}{l}\text { Clinical study: iron may diffuse from } \\
\text { ovarian endometriomas into the } \\
\text { adjacent ovarian tissue. However, } \\
\text { this phenomenon does not appear to } \\
\text { markedly affect ovarian function }{ }^{39}\end{array}$ \\
\hline & No data available & $\begin{array}{l}\text { Clinical study: disrupted iron homeostasis } \\
\text { in the peritoneal cavity of women } \\
\text { with endometriosis plays a role in the } \\
\text { pathogenesis of the disease }{ }^{40}\end{array}$ & $\begin{array}{l}\text { Review: accumulated data suggest that } \\
\text { disrupted iron metabolism may induce } \\
\text { oxidative stress in the peritoneal cavity } \\
\text { of endometriosis patients }{ }^{41}\end{array}$ \\
\hline & No data available & No data available & $\begin{array}{l}\text { Review: iron has a significant impact on } \\
\text { endometriotic-cell gene expression }{ }^{42}\end{array}$ \\
\hline Lead & $\begin{array}{l}\text { Clinical study: women suffering from } \\
\text { endometriosis presented lead urine } \\
\text { levels lower than control women }{ }^{26}\end{array}$ & No data available & No data available \\
\hline Magnesium & No data available & No data available & No data available \\
\hline Manganese & No data available & No data available & $\begin{array}{l}\text { Ex vivo study: the expression of } \\
\text { manganese superoxide dismutase in } \\
\text { endometriosis was persistently higher } \\
\text { than the control levels throughout the } \\
\text { menstrual cycle }{ }^{35}\end{array}$ \\
\hline Molybdenum & No data available & No data available & No data available \\
\hline Nickel & No data available & $\begin{array}{l}\text { Clinical study: blood samples from women } \\
\text { suffering from endometriosis contained } \\
\text { three times higher levels of nickel than } \\
\text { the healthy control group. The estrogenic } \\
\text { potential of nickel has been found to be } \\
\text { similar to that of estradiol }\end{array}$ & No data available \\
\hline Phosphorus & No data available & $\begin{array}{l}\text { Clinical study: the abnormal metabolism of } \\
\text { phosphorus and the higher levels of serum } \\
\mathrm{P} \text { may play a role in the pathogenesis of } \\
\text { endometriosis }^{32}\end{array}$ & No data available \\
\hline Potassium & No data available & No data available & No data available \\
\hline Selenium & No data available & No data available & No data available \\
\hline Silicon & No data available & No data available & No data available \\
\hline Sodium & No data available & No data available & No data available \\
\hline Zinc & $\begin{array}{l}\text { Clinical study: serum zinc levels } \\
\text { in women with endometriosis } \\
\text { are decreased, and this seems } \\
\text { to actually confirm that this } \\
\text { microelement can possibly affect the } \\
\text { multifactorial pathogenesis of the } \\
\text { disease }^{44}\end{array}$ & No data available & $\begin{array}{l}\text { Clinical study: intrafollicular zinc } \\
\text { levels were higher in women with } \\
\text { endometriosis who subsequently } \\
\text { became pregnant following in vitro } \\
\text { fertilization }{ }^{45}\end{array}$ \\
\hline
\end{tabular}

majority of results have been obtained in vitro in animal models or ex vivo in tissues of patients suffering from the disease versus case-control. Without randomized, placebo-controlled trials, it is currently very difficult to conclude any clinically and statistically significant benefit for these trace elements.

Even though trace elements could potentially be interesting, some of them are not authorized in food supplements
(Official Journal of the European Union). ${ }^{19}$ This is the case for some heavy metals such as cadmium, nickel, or lead.

Taking into account these studies, it could perhaps be considered to act on this gynecological disorder with food supplements containing trace elements (ie, nutripuncture). The assumption is that they could modulate estrogen receptors and thus influence the tropism and the survival 
of cells involved in endometriosis. By a modulation of the antioxidant system, they might also interact with various parameters influencing tissue biochemistry.

The company Pronutri (Carros, France) has developed an original formulation of eight different trace elements (authorized in food supplements by the European Union). It was initially tested in patients with problems of visual acuity, and the doctors discovered that women suffering from visual problems and also endometriosis benefited from an improvement of their health status. Therefore, the laboratory decided to conduct a first preliminary empiric and observational study in ten women suffering from a revised American Fertility Society Score (AFSr) Stages I-IV endometriosis, which has revealed positive effects in all women, within 60 days of treatment, in terms of regression of the disease and attenuation of symptoms, especially pelvic pain.

However, this was only indicative of a potential therapeutic effect, and the evidence was not of sufficient quality to recommend the treatment.

Therefore, the objective of this double-blind, randomized, placebo-controlled study (ClinicalTrials.gov NCT02437175) is to evaluate the efficacy of this combination of metal trace elements on the reduction of pain, in patients with an AFSr Stages II-IV endometriosis, combined or not to an adenomyosis, during a treatment period of 4 months.

\section{Patients and methods}

\section{Study design}

The design of the trial can be found in Figure 1. This is a prospective, interventional, randomized (two parallel groups), double-blind, placebo-controlled study. It will be conducted in 12 centers distributed in France and Belgium.

This study will be conducted in accordance with the guidelines of Good Clinical Practice and International
Conference on Harmonization and the last version of the Declaration of Helsinki.

It has already been submitted and approved by all central and peripheral ethics committees of France and Belgium, and the first patient was included on May 28, 2015.

Trace elements or placebo are proposed in the absence of any other treatment or as an add-on to current therapies, such as sexual hormones, nonsteroidal anti-inflammatory drugs, and surgery. At visit 1, patients must be either untreated or with the same treatments as mentioned above for a minimum of 2 months. A placebo run-in period of one menstrual cycle or 30 days for women in amenorrhea has been scheduled to eliminate the high placebo responders. After a 1:1 ratio randomization on Day 0 , the treatment with trace elements or placebo will last for 4 months (120 days). Four medical visits (Days -45 to $-30,0,60$, and 120) and two phone contacts or direct contacts (Days 30 and 90) will be set up, ideally between the seventh and the 21 st days of the menstrual cycle, if present.

\section{Study procedures}

The activities conducted at each visit, or contact, are described in Table 2.

The 30-item Endometriosis Health Profile (EHP-30) 20-22 $^{2}$ QoL questionnaire will be completed by the patient on Days 0,60 , and 120. During the entire study period, the patients will be asked to fill in a diary card in which they will record their pain (using a $100 \mathrm{~mm}$ Visual Analog Scale [VAS]), blood loss, NSAID (ibuprofen considered as the rescue medication, with a maximum dosage of $3 \times 600 \mathrm{mg} / \mathrm{d}$ ) or other drugs consumption, and adverse events (AEs) (serious or nonserious). Phone or direct intermediate contacts will be used to reinforce the compliance and to record potential AEs (serious or nonserious). A urinary pregnancy test will be done at each visit.

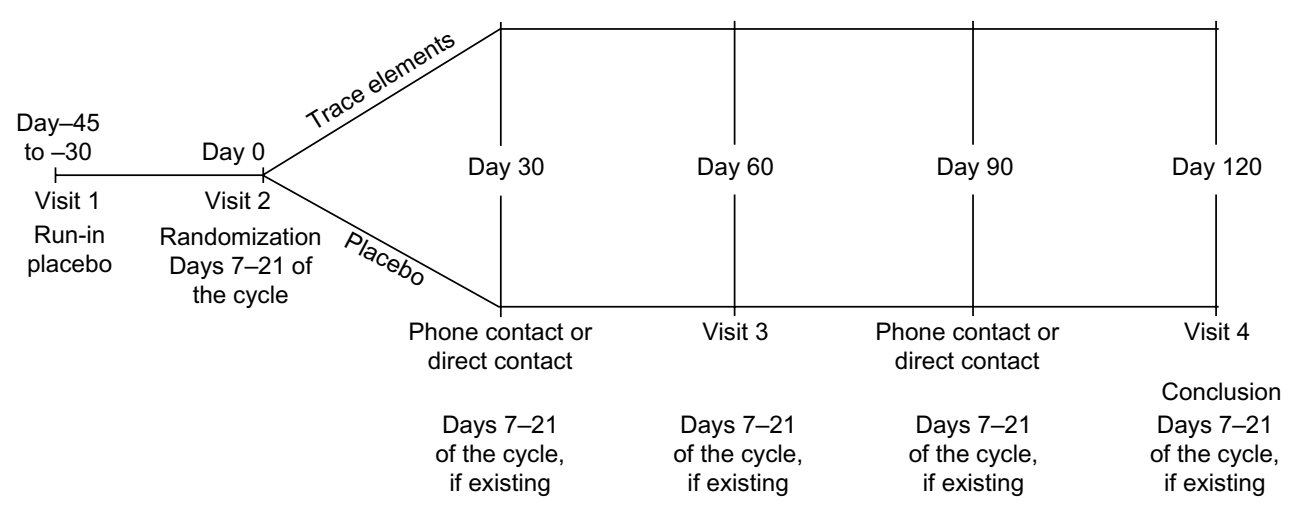

Figure I Trial design. 
Table 2 Study procedures

\begin{tabular}{|c|c|c|c|c|c|c|}
\hline Activity & $\begin{array}{l}\text { Visit I } \\
\text { Day }-45 /-30\end{array}$ & $\begin{array}{l}\text { Visit } 2 \\
\text { Day } 0\end{array}$ & $\begin{array}{l}\text { PC/DC } \\
\text { Day } 30\end{array}$ & $\begin{array}{l}\text { Visit } 3 \\
\text { Day } 60\end{array}$ & $\begin{array}{l}\text { PC/DC } \\
\text { Day } 90\end{array}$ & $\begin{array}{l}\text { Visit } 4 \\
\text { Day I } 20\end{array}$ \\
\hline Informed consent & $\bullet$ & & & & & \\
\hline Inclusion/exclusion criteria & $\bullet$ & $\bullet$ & & & & \\
\hline Demography & $\bullet$ & & & & & \\
\hline Medical history & $\bullet$ & & & & & \\
\hline Physical examination & $\bullet$ & $\bullet$ & & $\bullet$ & & $\bullet$ \\
\hline Urinary pregnancy test & $\bullet$ & $\bullet$ & & $\bullet$ & & $\bullet$ \\
\hline Pain Visual Analog Scale (100 mm) & $\bullet$ & ० & ० & ० & ○ & $\circ$ \\
\hline Endometriosis Health Profile-30 & & $\bullet$ & & $\bullet$ & & $\bullet$ \\
\hline Blood loss & & ○ & ० & $\circ$ & ○ & $\circ$ \\
\hline Ibuprofen (rescue medication) & $\bullet$ & ○ & ○ & ○ & ○ & ○ \\
\hline Other concomitant drugs & $\bullet$ & $\circ$ & $\circ$ & $\circ$ & $\circ$ & $\circ$ \\
\hline Randomization $(I: I)$ & & $\bullet$ & & & & \\
\hline Nonserious and serious adverse events & & $\bullet$ & $\circ$ & $\circ$ & $\circ$ & $\bullet$ \\
\hline Diary cards distribution & $\bullet$ & $\bullet$ & & $\bullet$ & & \\
\hline Diary cards retrieval & & $\bullet$ & & $\bullet$ & & $\bullet$ \\
\hline Study drug distribution & $\bullet$ & $\bullet$ & & $\bullet$ & & \\
\hline Study drug retrieval & & $\bullet$ & & $\bullet$ & & $\bullet$ \\
\hline Compliance (reinforcement and calculation) & & $\bullet$ & $\circ$ & $\bullet$ & $\circ$ & $\bullet$ \\
\hline Study conclusion & & & & & & $\bullet$ \\
\hline
\end{tabular}

Notes: $\bullet$, activity under the responsibility of the investigator; $\circ$, information collected via the patient's diary card. Abbreviation: PC/DC, phone contact or direct contact.

\section{Eligibility criteria}

Nonmenopausal woman (aged 18-45 years) consulting for pain related to an endometriosis (AFSr Stages II-IV), combined or not with an adenomyosis, previously confirmed by laparoscopy and/or laparotomy in the inclusion center, or obligatory by a biopsy (with or without MRI) in case the patient had not been followed in the center, treated or untreated, with sexual hormones, contraceptives or not (stable treatment for at least 2 months), or any other stabilized treatment will be included after giving their written informed consent. The time between surgery and inclusion will be at least 6 months. The pain measured on VAS at inclusion (Days -45 to -30 ) will be at least $40 \mathrm{~mm}$, and it cannot decrease by $>20 \%$ during the run-in placebo period.

Women with a Stage I endometriosis, with an adenomyosis without endometriosis, pregnant, or presenting with another pathology, which could interfere with endometriosis and/or adenomyosis, or the study follow-up will be excluded.

During the course of the study, surgery, any major therapeutic change, and confirmed pregnancy will constitute the elimination criteria.

\section{Study drug}

During the run-in period, patients will take a sequence of ten oral tablets (to crush in order to facilitate the sublingual absorption) in the order $1-10$, outside meal in the morning and in the evening.
After randomization, patients in the active treatment group will take Nutri Endo 1 (a sequence of ten oral tablets to crush in the order 1-10, outside meal in the morning) and Nutri Endo 2 (a sequence of ten oral tablets to crush in the order 1-10, outside meal in the evening) for 120 days (Laboratoires Pronutri, Carros, France) (Table 3). Patients in the placebo group will follow the same schedule with placebo tablets replacing Nutri Endo 1 and 2.

\section{Objectives and endpoints}

The primary objective of the study will be to assess the efficacy of metal trace elements versus placebo on the reduction of pain. The secondary objectives will be to evaluate the efficacy of metal trace elements versus placebo on the improvement of the QoL and on the decrease of the rescue medication consumption. The safety of metal trace elements versus placebo will also be assessed through the recording of potential nonserious (AEs) and serious adverse events (SAEs) during the entire study period.

The primary endpoint will be the change in the area under the curve (AUC) of pain, as determined by VAS, between the run-in placebo period and the 120-day treatment period in the two treatment groups.

The secondary endpoints will be the change in the total score of the EHP-30 QoL questionnaire between Day 60 or 120 and Day 0, the number of ibuprofen tablets consumed during the 120-day treatment phase, and the frequency of 
Table 3 Composition of Nutri Endo I and Nutri Endo 2

\begin{tabular}{ll}
\hline Ingredient & Daily dose \\
\hline Nutri Endo I & \\
Calcium & $21.90 \mathrm{mg}$ \\
Magnesium & $4.37 \mathrm{mg}$ \\
Zinc & $0.80 \mathrm{mg}$ \\
Manganese & $0.11 \mathrm{mg}$ \\
Potassium & $0.07 \mathrm{mg}$ \\
Sodium & $0.02 \mathrm{mg}$ \\
Copper & $53.00 \mu \mathrm{g}$ \\
Iron & $0.26 \mu \mathrm{g}$ \\
Nutri Endo 2 & \\
Calcium & $22.94 \mathrm{mg}$ \\
Magnesium & $5.50 \mathrm{mg}$ \\
Zinc & $0.54 \mathrm{mg}$ \\
Manganese & $0.18 \mathrm{mg}$ \\
Potassium & $0.12 \mathrm{mg}$ \\
Copper & $52.00 \mu \mathrm{g}$ \\
Iron & $4.80 \mu \mathrm{g}$ \\
Sodium & $0.08 \mathrm{mg}$ \\
\hline
\end{tabular}

AEs and SAEs (considered related or not to the treatment) in the two treatment groups.

A confirmed pregnancy during the study will be an elimination criterion. The reason is not linked to any potential risk of the study drug on the pregnancy outcomes but to the fact that pregnancy can modify pain and therefore constitutes a significant pain measurement bias. For these reasons, pregnancy will not be considered as an AE but as a potentially positive outcome if the patient wanted to be pregnant. After elimination from the study, the patient will be followed-up by her gynecologist until delivery as usual.

\section{Sample size justification}

A sample size of 23 completed patients per group will have $90 \%$ power to detect a difference in the percentage change in pain AUC of $20 \%$ between trace elements and placebo (based on a decrease of $10 \%$ in the placebo group, a decrease of $30 \%$ in the trace elements group, and a common standard deviation of $20 \%$ ), using an independent Student's $t$-test with an alpha risk of 5\%. Taking into account the pilot characteristic of the study, the absence of preliminary data and a drop-out rate after the run-in period of $15 \%-20 \%, 60$ patients will be enrolled in order to complete 50 patients ( 25 trace elements and 25 placebo). Any drop-out patient will be replaced until the number of 50 completed patients has been reached.

\section{Statistical analyses}

The intention-to-treat cohort will be the primary population for the evaluation of efficacy and safety. It will include all randomized patients who will have taken at least one dose of treatment and for whom at least one result concerning efficacy or safety has been recorded after randomization.

The secondary population will be the per protocol cohort. It will include all patients having completed the study without any major deviation from the protocol and in whom the global compliance (determined by counting the remaining treatment tablets) is at least $80 \%$.

A paper case report form will be used to collect the data. After double data entry and resolution of all queries, the data will be migrated into the software IBM-SPSS Statistics Version 21.0 for statistical analyses. Missing values will not be replaced. The last observation carried forward will be determined for all parameters in noncompleted patients. Descriptive statistics will be used to characterize the patients at baseline. Student's $t$-test (for continuous variables) and chi-square test, Fisher's exact test, or Mann-Whitney test (for discrete variables) will be used to compare the two treatment groups at baseline. The primary and secondary efficacy endpoints will be compared between the two treatment groups using the independent Student's $t$-test. When more than two time points are considered to compare the two groups, analyses of variance for repeated measures, with the factor "time," "treatment," and "time $\times$ treatment interaction" will be used, followed when significant by the appropriate post hoc tests. Fisher's exact test will be used to compare the frequencies of AEs, SAEs, related AEs, and related SAEs between the two treatment groups. For the primary endpoint, a $P$-value $<5 \%$ will be considered statistically significant. For all the other inferential analyses, $P$-values $<5 \%$ will be considered indicative only of potential differences between the two treatment groups.

\section{Discussion}

To our knowledge, the potential efficacy of metal trace elements against endometriosis-induced pelvic pain has never been tested in a double-blind, randomized, placebocontrolled trial. Therefore, this is the main originality of this pilot study.

It was initially scheduled to identify and to recruit the patients on the sole basis of biopsy. However, it appeared that it could seriously prolong the inclusion period needed to achieve the requested sample size because in practice, some centers do not perform a biopsy and because in case of relapse (frequent for endometriosis), most of the time, a biopsy is not performed at all. Therefore, because of the chronicity of the disease and accuracy of laparoscopic/visual diagnosis of endometriosis, 
we confirmed the possibility to include a patient without recent histology. The diagnosis of endometriosis by visual inspection of the lesions will be based on the experience of the surgeon, ${ }^{23}$ and this is a key factor to obtain a high correlation between macroscopic visual diagnosis and pathological diagnosis of a biopsy specimen. The visual appearance consistent with the diagnosis of endometriosis has a reported sensitivity of $94 \%-97 \%$ and a specificity of $77 \%-85 \%$, using histological diagnosis as a reference. ${ }^{24}$ This is the reason why we decided to reserve this type of eligibility only to patients attending recognized and trained endometriosis centers. ${ }^{25}$

For ethical reasons, it was not possible to let the patients without any golden standard treatments. Therefore, this is a particular challenge of this study to be able to show a superiority of metal trace elements versus placebo in the context of an add-on therapy.

Instead of measuring pelvic pain at specific, fixed, and limited time points, we have decided to record it every day during the placebo run-in period and the 120-day treatment phase and to compare the changes versus baseline in pain AUCs in the placebo and metal trace elements-treated groups. Together with the analysis of the QoL by means of the EHP-30 questionnaire, it will allow us to conclude to a potential positive effect of metal trace elements versus placebo on the QoL in endometriosis patients, which is at the end of the day the best and most important clinical objective to achieve in order to decrease the burden of endometriosis.

There is an important limitation to the study in terms of mechanistic approach. While, we were asked by the company Pronutri to evaluate its product in a strict double-blind, randomized controlled study, as is the case for the majority of multicomponent drugs, plant extracts, food supplements, and homeopathic treatments, it will be impossible to know which trace element(s) is(are) responsible for an eventual positive effect in endometriosis-induced pelvic pain. At the opposite, if we fail to achieve the primary endpoint of the study, it will never be possible to improve these products. Therefore, this is a kind of all or none approach, which is frustrating for scientists, but we have to live with it. Ultimately, it is the QoL of our patients that is important and not the mechanism of action of a drug, whatever it is.

\section{Acknowledgments}

The authors are grateful to the other participating members (by alphabetical order): Dr Agostini-Ferrandes Aubert (Marseille, France), Dr Conti Virginie (Namur, Belgium), Dr Friederich
Ludovic (Paris, France), Dr Jamin Christian (Paris, France), Dr Legros Séverine (Ans, Belgium), Dr Lestrade Florence (Metz-Thionville, France), Dr Mine Jean-Michel (Charleroi, Belgium), Dr Nataf Jocelyne (Brignoles, France), Dr Panel Pierre (Le Chesnay, France), Dr Ripart Sylvie (Nîmes, France), Dr Rongières Catherine (Schiltigheim, France), and Dr Walravens Françoise (Charleroi, Belgium). They are also grateful to Jacques Bruhwyler (ECSOR sa/nv) for helping in the preparation of this manuscript. This study is entirely supported by Laboratoires Pronutri.

\section{Disclosure}

Didier Oberweis, Patrick Madelenat, and Michelle Nisolle are the principal investigators of this study. Their centers have received a financial support from Laboratoires Pronutri just for conducting this study. Etienne Demanet is the clinical research coordinator from the principal investigator's center (Dr Oberweis). He contributed to the revision of the protocol and to the setup of the study. The authors report no other conflicts of interest in this work.

\section{References}

1. Missmer SA, Hankinson SE, Spiegelman D, Barbieri RL, Marshall LM, Hunter DJ. Incidence of laparoscopically confirmed endometriosis by demographic, anthropometric, and lifestyle factors. Am J Epidemiol. 2004;160:784-796.

2. Peterson CM, Johnstone EB, Hammoud AO, et al; ENDO Study Working Group. Risk factors associated with endometriosis: importance of study population for characterizing disease in the ENDO study. Am $J$ Obstet Gynecol. 2013;208:451.e1-e11.

3. Donnez J, Chantraine F, Nisolle M. The efficacy of medical and surgical treatment of endometriosis-associated infertility: arguments in favour of a medico-surgical aproach. Hum Reprod Update. 2002;8:89-94.

4. Heilier JF, Donnez J, Lison D. Organochlorines and endometriosis: a mini-review. Chemosphere. 2008;71:203-210.

5. Giudice LC, Kao LC. Endometriosis. Lancet. 2004;364:1789-1799.

6. Schulte-Uebbing C. Hohergradige endometriose: die rolle von endokrinen disruptoren und inflammation [High-grade endometriosis: the role of endocrine disruptors and inflammation]. Zeitschrift Umwelt Medizin Gesellschaft. 2011;24:S43-S46. German.

7. Fedele L, Bianchi S, Zanconato G, Berlanda N, Raffaelli R, Fontana E. Laparoscopic excision of recurrent endometriomas: long-term outcome and comparison with primary surgery. Fertil Steril. 2006;85:694-699

8. Chapron C, Vercellini P, Barakat H, Vieira M, Dubuisson JB Management of ovarian endometriomas. Hum Reprod Update. 2002;8:591-597.

9. Jones KD, Sutton CJ. Laparoscopic management of ovarian endometriomas: a critical review of current practice. Curr Opin Obstet Gynecol. 2000;12:309-315.

10. Koga K, Takemura Y, Osuga Y, et al. Recurrence of ovarian endometrioma after laparoscopic excision. Hum Reprod. 2006;21:2171-2174.

11. Brown J, Farquhar C. Endometriosis: an overview of Cochrane Reviews. Cochrane Database Syst Rev. 2014;3:CD009590.

12. Darbre PD. Metalloestrogens: an emerging class of inorganic xenoestrogens with potential to add to the oestrogenic burden of the human breast. J Appl Toxicol. 2006;26:191-197. 
13. Johnson MD, Kenney N, Stoica A, et al. Cadmium mimics the in vivo effects of estrogen in the uterus and mammary gland. Nat Med. 2003;9:1081-1084.

14. Stoica A, Katzenellenbogen BS, Martin MB. Activation of estrogen receptor-alpha by the heavy metal cadmium. Mol Endocrinol. 2000; $14: 545-553$

15. Defrere S, Lousse JC, Gonzalez-Ramos R, Colette S, Donnez J, Van Langendonckt A. Potential involvement of iron in the pathogenesis of peritoneal endometriosis. Mol Hum Reprod. 2008;14:377-385.

16. Agarwal A, Aponte-Mellado A, Premkumar BJ, Shaman A, Gupta S. The effects of oxidative stress on female reproduction: a review. Reprod Biol Endocrinol. 2012;10:49.

17. Szczepanska M, Kozlik J, Skrzypczak J, Mikołajczyk M. Oxidative stress may be a piece in the endometriosis puzzle. Fertil Steril. 2003;79:1288-1293.

18. Augoulea A, Alexandrou A, Creatsa M, Vrachnis N, Lambrinoudaki I. Pathogenesis of endometriosis: the role of genetics, inflammation and oxidative stress. Arch Gynecol Obstet. 2012;286:99-103.

19. Official Journal of the European Union; L314/36; Rule 1170/2009 of November 30, 2009.

20. Jones G, Jenkinson C, Taylor N, Mills A, Kennedy S. Measuring quality of life in women with endometriosis: tests of data quality, score reliability, response rate and scaling assumptions of the endometriosis health profile questionnaire. Hum Reprod. 2006;21:2686-2693.

21. Jenkinson C, Kennedy S, Jones G. Evaluation of the American version of the 30-item endometriosis health profile (EHP-30). Qual Life Res. 2008;17:1147-1152.

22. Morotti M, Sozzi F, Remorgida V, Venturini PL, Ferrero S. Dienogest in women with persistent endometriosis-related pelvic pain during norethisterone acetate treatment. Eur J Obstet Gynecol Reprod Biol. 2014;183:188-192.

23. Dunselman GA, Vermeulen N, Becker C, et al; European Society of Human Reproduction and Embryology. ESHRE guideline: management of women with endometriosis. Hum Reprod. 2014;29:400-412.

24. Wykes CB, Clark TJ, Khan KS. Accuracy of laparoscopy in the diagnosis of endometriosis: a systematic quantitative review. BJOG. 2004;111:1204-1212.

25. Stegmann BJ, Sinaii N, Liu S, et al. Using location, color, size, and depth to characterize and identify endometriosis lesions in a cohort of 133 women. Fertil Steril. 2008;89:1632-1636.

26. Pollack AZ, Louis GM, Chen Z, et al. Trace elements and endometriosis: the ENDO study. Reprod Toxicol. 2013;42:41-48.

27. Silva N, Tennekoon K, Senanayake H, Samarakoon S. Metalloestrogen cadmium stimulates proliferation of stromal cells derived from the eutopic endometrium of women with endometriosis. Taiwan J Obstet Gynecol. 2013;52:540-545.

28. Heilier JF, Verougstraete V, Nackers F, Tonglet R, Donnez J, Lison D. Assessment of cadmium impregnation in women suffering from endometriosis: a preliminary study. Toxicol Lett. 2004;154:89-93.

29. Heilier JF, Donnez J, Verougstraete V, et al. Cadmium, lead and endometriosis. Int Arch Occup Environ Health. 2006;80:149-153.
30. Itoh H, Iwasaki M, Nakajima Y, et al. A case-control study of the association between urinary cadmium concentration and endometriosis in infertile Japanese women. Sci Total Environ. 2008;402:171-175.

31. Wang Y, Zhang M, Xie F, et al. Upregulation of alphadelta-1 calcium channel subunit in the spinal cord contributes to pelvic organ crosssensitization in a rat model of experimentally-induced endometriosis. Neurochem Res. 2015;40:1267-1273. Chinese.

32. Lu BC, Zhang XM. [Associations of metabolism of lipid, calcium and phosphate in endometriosis]. Zhonghua $\mathrm{Fu} C h a n \mathrm{Ke} \mathrm{Za} \mathrm{Zhi.}$ 2008;43:185-188.

33. Barcena de Arellano ML, Munch S, Arnold J, Helbig S, Schneider A, Mechsner S. Calcium-binding protein expression in peritoneal endometriosisassociated nerve fibres. Eur J Pain. 2013;17:1425-1437.

34. Turgut A, Ozler A, Goruk NY, Tunc SY, Evliyaoglu O, Gül T. Copper, ceruloplasmin and oxidative stress in patients with advanced-stage endometriosis. Eur Rev Med Pharmacol Sci. 2013;17:1472-1478.

35. Ota H, Igarashi S, Hatazawa J, Tanaka T. Immunohistochemical assessment of superoxide dismutase expression in the endometrium in endometriosis and adenomyosis. Fertil Steril. 1999;72:129-134.

36. Sanchez AM, Papaleo E, Corti L, et al. Iron availability is increased in individual human ovarian follicles in close proximity to an endometrioma compared with distal ones. Hum Reprod. 2014;29:577-583.

37. Mori M, Ito F, Shi L, et al. Ovarian endometriosis-associated stromal cells reveal persistently high affinity for iron. Redox Biol. 2015;6:578-586.

38. Alvarado-Diaz CP, Nunez MT, Devoto L, González-Ramos R. Iron overload-modulated nuclear factor kappa-B activation in human endometrial stromal cells as a mechanism postulated in endometriosis pathogenesis. Fertil Steril. 2015;103:439-447.

39. Benaglia L, Paffoni A, Mangiarini A, et al. Intrafollicular iron and ferritin in women with ovarian endometriomas. Acta Obstet Gynecol Scand. 2015;94:646-653.

40. Polak G, Wertel I, Tarkowski R, Kotarski J. [Peritoneal fluid iron levels in women with endometriosis]. Ginekol Pol. 2010;81:20-23. Polish.

41. Polak G, Wertel I, Kwasniewski W, Derewianka-Polak M, Kotarski J. [The role of iron metabolism and oxidative stress in the pathogenesis of endometriosis]. Ginekol Pol. 2013;84:62-64. Polish.

42. Kobayashi H, Yamada Y, Kanayama S, et al. The role of iron in the pathogenesis of endometriosis. Gynecol Endocrinol. 2009;25:39-52.

43. Bloom MS, Parsons PJ, Steuerwald AJ, et al. Toxic trace metals and human oocytes during in vitro fertilization (IVF). Reprod Toxicol. 2010;29:298-305.

44. Messalli EM, Schettino MT, Mainini G, et al. The possible role of zinc in the etiopathogenesis of endometriosis. Clin Exp Obstet Gynecol. 2014;41:541-546.

45. Singh AK, Chattopadhyay R, Chakravarty B, Chaudhury K. Markers of oxidative stress in follicular fluid of women with endometriosis and tubal infertility undergoing IVF. Reprod Toxicol. 2013;42:116-124.
Nutrition and Dietary Supplements

\section{Publish your work in this journal}

Nutrition and Dietary Supplements is an international, peer-reviewed, open access journal focusing on research into nutritional requirements in health and disease, impact on metabolism and the identification and optimal use of dietary strategies and supplements necessary for normal growth and development. The journal welcomes papers covering

\section{Dovepress}

original research, basic science, clinical \& epidemiological studies, reviews and evaluations, guidelines, expert opinion and commentary, case reports and extended reports. The manuscript management system is completely online and includes a very quick and fair peer-review system, which is all easy to use. 